\title{
Influence of the Blue Coral Heliopora coerulea on Scleractinian Coral Larval Recruitment
}

\author{
Michael Atrigenio, Porfirio Aliño, and Cecilia Conaco \\ Marine Science Institute, College of Science, University of the Philippines Diliman, Quezon City, Philippines \\ Correspondence should be addressed to Michael Atrigenio; matrigenio@gmail.com
}

Received 16 November 2016; Revised 10 March 2017; Accepted 2 April 2017; Published 12 April 2017

Academic Editor: Yehuda Benayahu

Copyright (C) 2017 Michael Atrigenio et al. This is an open access article distributed under the Creative Commons Attribution License, which permits unrestricted use, distribution, and reproduction in any medium, provided the original work is properly cited.

\begin{abstract}
The octocoral Heliopora coerulea has emerged as one of the most dominant reef-building corals in the Bolinao Reef Complex, northern Philippines. One of the possible mechanisms that may contribute to the success of $H$. coerulea over scleractinian corals is its ability to compete effectively for space on the reef by inhibiting the settlement of coral larvae in its immediate vicinity. To determine whether $H$. coerulea can indeed inhibit larval recruitment, settlement tiles were deployed inside $H$. coerulea aggregations or on hard substrate at a distance of about 2 to 3 meters away. After three months of deployment, only a single $H$. coerulea recruit was observed on tiles placed within aggregations whereas many different coral recruits were observed on tiles placed on substrate away from the blue coral. These results suggest that adult $H$. coerulea can inhibit the settlement of scleractinian larvae. This effect may be mediated by various mechanisms, such as the production of allelopathic compounds, deployment of mesenterial filaments, and sweeper tentacles. However, further studies are needed to determine the modes of competition that are used by the coral.
\end{abstract}

\section{Introduction}

It is widely recognized that space is limited in reef ecosystems. Hence, reef-associated organisms, including scleractinian corals, developed competitive mechanisms that enable them to occupy, expand, and protect their territories in pursuit of food and to ensure reproductive success [1]. Mechanisms for competition in reef ecosystems occur in various forms, including overgrowth and direct consumption of neighboring organisms, or through allelopathy $[1,2]$.

Although the role of allelopathy in shaping the structure of a reef community is well-established only a few studies have examined its effect on the settlement of juvenile corals, a mechanism that could effectively exclude late entrants from conquering the occupied space. Allelopathy is likely the means by which the soft coral Xenia puertogalerae [3] and the scleractinian coral Porites cylindrica [4] established dominance and developed monospecific stands in some Philippine reefs. Because allelopathic compounds are released in the water column, hydrographic processes play a role in dispersing them. Therefore, the prevailing current direction helps shape the resulting distribution of subordinate organisms or the general pattern of the underwater landscape. For example, a study on the Great Barrier Reef revealed that allelopathic compounds emitted by Sinularia flexibilis can inhibit the recruitment of juvenile scleractinian corals located downstream of exuding colonies [5].

Although allelopathy is common in octocorals, larval recruitment of scleractinian corals could also be influenced by other mechanisms, such as the extrusion of mesenterial filaments [6] and deployment of sweeper tentacles [7]. For example, the Caribbean octocoral Erythropodium extends long sweeper tentacles to sweep and clear all nearby substrate of any potential competitors [8].

The blue coral, Heliopora coerulea (order Helioporacea), is one of the most dominant reef-building corals in the Bolinao Reef Complex, northern Philippines. It constituted about $1 \%$ of coral cover on the reef in the 1990s [9] and increased to more than $50 \%$ a couple of decades later [10]. The factors contributing to this increase remain to be determined. The present study thus sought to explore whether $H$. coerulea, like other octocorals, exhibits inhibitory effects on the larvae of other corals. A field experiment was conducted to test this hypothesis. 


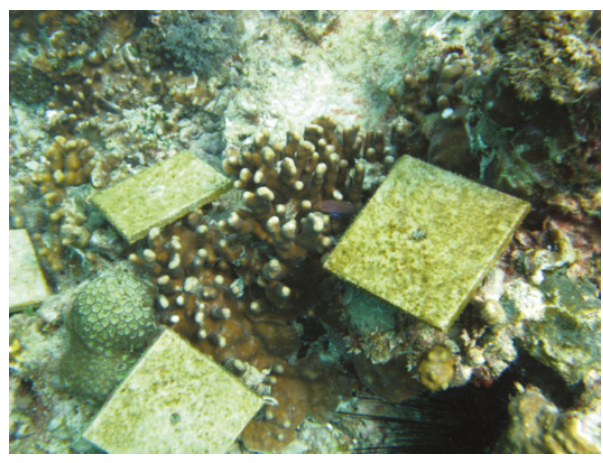

(a)

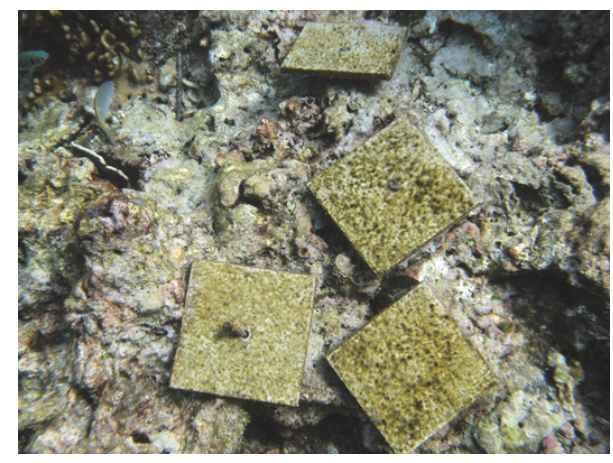

(b)

FIGURE 1: Four sets of four tiles each were placed either directly inside H. coerulea aggregations (a) or on rocky substrate away from the coral (b). Replicate sets of tiles were placed at least 2-3 m away from each other within a reef area of about $10 \times 10 \mathrm{~m}$ at 5-6 m depth in the Malilnep channel, Bolinao Reef Complex, northwestern Philippines.

\section{Materials and Methods}

2.1. Recruitment Assay. The study was conducted within a 10 $\times 10 \mathrm{~m}$ area at a depth of 5 to $6 \mathrm{~m}$ on the reef crest of Malilnep channel in the Bolinao Reef Complex in northwestern Philippines (N16.44011, E119.93533). This site was chosen because of high larval entrainment demonstrated in past studies $[9,11]$ compared to other areas in the reef complex, hence, ensuring the availability of larval recruits during the experiment. Fiberreinforced cement tiles [12] each measuring $100 \times 100 \times$ $7 \mathrm{~mm}$ (total surface area $228 \mathrm{~cm}^{2}$ ) were placed either inside $H$. coerulea aggregations ranging from half meter to two meters in diameter or in open spaces with dead coral or rocky substrate located about 2-3 meters away from $H$. coerulea colonies, scleractinian corals, and other reef biota (Figure 1). Four replicates consisting of four tiles per set were used for each treatment or a total of 16 tiles per treatment. The settlement tiles were fixed horizontally to the substrate by hammering two-inch concrete nails through a hole bored at the center of each tile. Settlement tiles were deployed for three months from April to June 2012, which corresponds to the reported peak spawning period of scleractinian corals, as well as $H$. coerulea, in Bolinao $[13,14]$. After the exposure period, tiles were retrieved and newly settled corals were identified to genus level by microscopic examination of all the sides of the tiles. Coral recruits were identified to the lowest taxonomic classification based on an available identification guide [15].

2.2. Statistical Analyses. To determine if $H$. coerulea significantly inhibited scleractinian coral recruitment, nonparametric statistical analysis, specifically the chi-square test, was conducted. The null hypothesis is that there is no difference in the number of recruits that settle on tiles placed adjacent to $H$. coerulea versus those placed at a distance away from the coral.

\section{Results and Discussion}

Successful recruitment is an important contributor to reef resilience in the face of environmental perturbation [16-18].

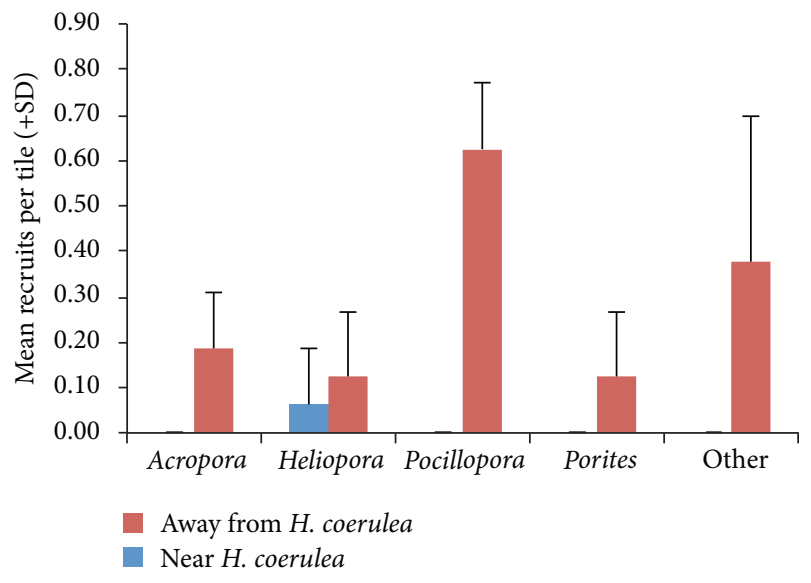

FIGURE 2: Composition of recruits on settlement tiles placed either inside $H$. coerulea aggregations (blue bars) or in open space away from $H$. coerulea (red bars).

Interestingly, although recruitment tiles were deployed during the predicted period of mass spawning of scleractinian corals and $H$. coerulea in Bolinao $[13,14]$, only 1 out of 16 tiles placed inside $H$. coerulea aggregations contained any visible recruits. The single recruit found on these settlement tiles was a blue coral juvenile (Figure 2). On the other hand, coral recruits belonging to various scleractinian genera, as well as the blue coral, were observed on 13 out of 16 tiles placed on rocky substrate away from $H$. coerulea aggregations. Most of the recruits were observed on the sides and bottom of the tiles with none settling on the top surface, which is consistent with reports from other studies [3].

Tiles placed adjacent to $H$. coerulea colonies showed a very low density of recruitment $(0.06 \pm 0.13$ recruits per tile) (Table 1). In contrast, more larval recruits settled on tiles that were placed away from $H$. coerulea $(1.44 \pm 0.31$ recruits per tile). The chi-square test showed a significant difference between treatment and control tiles $(p=0.0001)$. These findings suggest that the presence of $H$. coerulea can inhibit larval coral settlement. However, the exact mechanism 


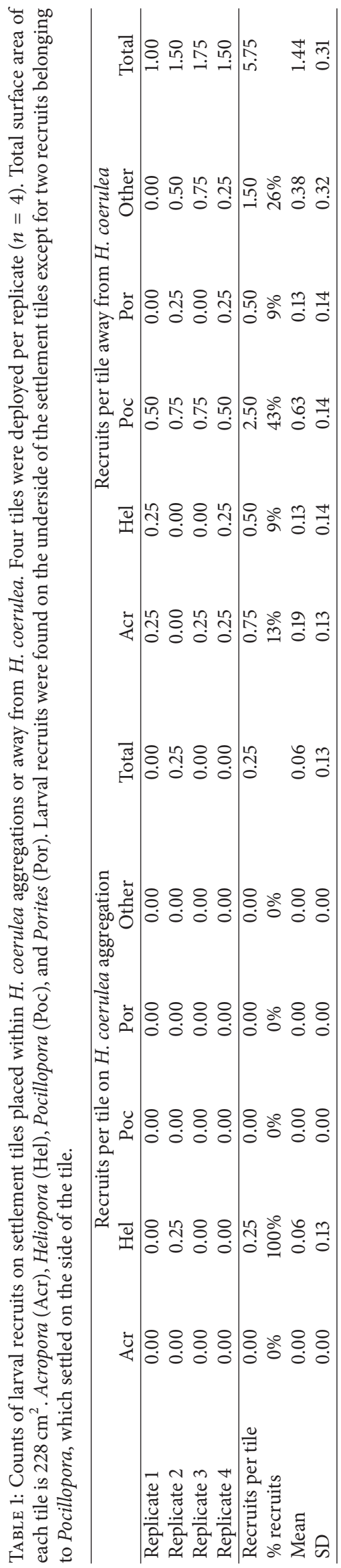


involved is still unknown. While allelopathy is a common mechanism by which cnidarians can inhibit competition [3, 19-21], we cannot yet rule out other possible mechanisms, including the consumption of settling larvae by $H$. coerulea or the deployment of sweeper tentacles [8].

Juvenile corals belonging to Pocillopora comprised 43\% of recruits identified on tiles placed away from $H$. coerulea (Figure 2 and Table 1), followed by Acropora (13\%), Heliopora (9\%), Porites (9\%), and other species (26\%). Interestingly, only a single $H$. coerulea juvenile was found on the tiles placed directly on $H$. coerulea colonies. This suggests that $H$. coerulea can inhibit the settlement of larvae of scleractinian corals, but in addition it can also exert a negative influence on conspecifics. The negative effect of corals on conspecifics has previously been documented for corals, such as Platygyra daedalea and Fungia fungites, which have been found to produce chemicals with toxic effects on their own larvae [21].

The composition of recruits observed in this study is consistent with observations from other coral recruitment studies that have been conducted in the Bolinao Reef Complex [11, 22]. Most corals in the area, including Acropora, Heliopora, Porites, and Favia, spawn gametes or release larvae during the months of April and May [22]. The annual coral spawning event in Bolinao is extended, with some corals starting to spawn as early as March. However, similar to this study, the most common and abundant recruits reported in studies from the Bolinao Reef Complex belong to Pocillopora, which is known to release planulae every month [23]. A study of coral recruitment in the Malilnep channel using the same recruitment substrate used in the present study yielded a higher number of Acropora and Pocillopora recruits compared to other species [11].

$H$. coerulea larvae have a short larval duration and their range of dispersal is determined largely by prevailing water currents on the reef [24]. In this study, however, we did not determine the influence of water turbulence or local currents in the area where the tiles were placed. Further studies that look at recruitment in other areas on the reef and other time points need to be conducted. Further research is also needed to elucidate the exact mechanisms behind the inhibitory effect of $H$. coerulea on larval recruitment. We lack evidence concerning the competitive mechanisms involved, such as the possible deployment of mesenterial filaments or sweeper tentacles, because we did not conduct nighttime observations to detect these types of behaviors, which often are exhibited nocturnally by corals. Allelopathy also is a commonly used competitive mechanism in octocorals and has been observed in S. flexibilis [5], X. puertogalerae [3], Lobophytum pauciflorum, Sinularia pavida, Xenia sp. aff. danae [19], and Sarcophyton glaucum [25]. It would be of interest to determine whether $H$. coerulea exudes allelopathic chemicals or uses other competitive mechanisms.

The inhibitory effect exhibited by $H$. coerulea can reinforce ecological feedback [26], which could lead to more persistent $H$. coerulea dominance. Competition with $H$. coerulea can adversely affect scleractinian coral growth, fecundity, and survival [27], resulting in further reduction of larval supply that may already be low due to the decreased number of scleractinian adults in the area. These factors bring about the Allee effect, whereby coral recruitment declines due to reduced fertilization success exacerbated by declining coral density [28]. This indicates that a reef with a high percent cover of $H$. coerulea is unlikely to be a hospitable environment for the establishment of new scleractinian coral recruits. The ability of $H$. coerulea to inhibit larval settlement may thus have far-reaching implications on future reef community structure.

\section{Conflicts of Interest}

The authors declare that there are no conflicts of interest regarding the publication of this paper.

\section{Acknowledgments}

This study was conducted under the auspices of the Department of Science of Technology through the RESILIENTSEAS project. The authors received support from the University of the Philippines System Emerging Interdisciplinary Research Grant (OVPAA-EIDR-C04-005). R. Martinez, F. Panga, and M. Deocadez assisted in the field surveys. This is contribution 450 of the University of the Philippines Marine Science Institute.

\section{References}

[1] N. E. Chadwick and K. M. Morrow, "Competition among sessile organisms on coral reefs," in Coral Reefs: An Ecosystem in Transition, Z. Dubinsky and N. Stambler, Eds., pp. 347-371, Springer, 2011.

[2] J. C. Lang and E. A. Chornesky, "Competition between scleractinian reef corals: a review of mechanisms and effects," in Coral Reefs Ecosystems of the World 25, Z. Dubinsky, Ed., pp. 209-252, Elsevier, Amsterdam, The Netherlands, 1990.

[3] M. P. Atrigenio and P. M. Aliño, "Effects of the soft coral Xenia puertogalerae on the recruitment of scleractinian corals," Journal of Experimental Marine Biology and Ecology, vol. 203, no. 2, pp. 179-189, 1996.

[4] R. M. Dizon and H. T. Yap, "Coral responses in single- and mixed-species plots to nutrient disturbance," Marine Ecology Progress Series, vol. 296, pp. 165-172, 2005.

[5] M. Maida, P. W. Sammarco, and J. C. Coll, "Preliminary evidence for directional allelopathic effects of the soft coral Sinularia flexibilis (Alcyonacea: Octocorallia) on scleractinian coral recruitment," Bulletin of Marine Science, vol. 56, no. 1, pp. 303-311, 1995.

[6] J. C. Lang, "Interspecific aggression by scleractinian corals II. Why the race is not always to the swift," Bulletin of Marine Science, vol. 23, pp. 260-279, 1973.

[7] C. A. Richardson, P. Dustan, and J. C. Lang, "Maintenance of living space by sweeper tentacles of Montastrea cavernosa, a caribbean reef coral," Marine Biology, vol. 55, no. 3, pp. 181-186, 1979.

[8] E. D. Lapid, J. Wielgus, and N. E. Chadwick-Furman, "Sweeper tentacles of the brain coral Platygyra daedalea: induced development and effects on competitors," Marine Ecology Progress Series, vol. 282, pp. 161-171, 2004. 
[9] M. P. Atrigenio, Patterns and processes of coral recruitment in some Philippines reefs [M.S. thesis], University of the Philippines Marine Science Institute, 1995.

[10] M. B. Vergara, Coral community structure of the Bolinao Reef System northwestern Philippines [M.S. thesis], University of the Philippines Marine Science Institute, 2009.

[11] M. V. Baria, Coral recruitment and larval rearing for reef restoration [M.S. thesis], University of the Philippines Marine Science Institute, 2010.

[12] Y. Nozawa, K. Tanaka, and J. D. Reimer, "Reconsideration of the surface structure of settlement plates used in coral recruitment studies," Zoological Studies, vol. 50, no. 1, pp. 53-60, 2011.

[13] K. C. Vicentuan, J. R. Guest, M. V. Baria et al., "Multi-species spawning of corals in north-western Philippines," Coral Reefs, vol. 27, no. 1, p. 83, 2008.

[14] R. D. Villanueva, "Cryptic speciation in the stony octocoral Heliopora coerulea: temporal reproductive isolation between two growth forms," Marine Biodiversity, vol. 46, no. 2, pp. 503$507,2016$.

[15] S. C. English, C. Wilkinson, and V. Baker, Survey Manual for Tropical Marine Resources, Australian Institute of Marine Science, Townsville Australia, 1997.

[16] R. P. M. Bak and M. S. Engel, "Distribution, abundance and survival of juvenile hermatypic corals (Scleractinia) and the importance of life history strategies in the parent coral community," Marine Biology, vol. 54, no. 4, pp. 341-352, 1979.

[17] D. Glassom, D. Zakai, and N. E. Chadwick-Furman, "Coral recruitment: a spatio-temporal analysis along the coastline of Eilat, northern Red Sea," Marine Biology, vol. 144, no. 4, pp. 641651, 2004.

[18] S. Martinez and A. Abelson, "Coral recruitment: the critical role of early post-settlement survival," ICES Journal of Marine Science, vol. 70, no. 7, pp. 1294-1298, 2013.

[19] P. W. Sammarco, J. C. Coll, S. La Barre, and B. Willis, "Competitive strategies of soft corals (Coelenterata: Octocorallia): allelopathic effects on selected scleractinian corals," Coral Reefs, vol. 1, no. 3, pp. 173-178, 1983.

[20] P. M. Aliño, P. W. Sammarco, and J. C. Coll, "Competitive strategies in soft corals (Coelenterata, Octocorallia). IV. Environmentally induced reversals in competitive superiority," Marine Ecology Progress Series, vol. 81, no. 2, pp. 129-145, 1992.

[21] R. J. Fearon and A. M. Cameron, "Larvotoxic extracts of the hard coral Goniopora tenuidens: allelochemicals that limit settlement of potential competitors?" Toxicon, vol. 34, no. 3, pp. 361-367, 1996.

[22] P. Harrison, R. Villanueva, and D. de la Cruz, Coral Reef Restoration Using Mass Coral Larval Reseeding, Australian Centre for International Agricultural Research, Canberra, Australia, 2016.

[23] R. D. Villanueva, H. T. Yap, and M. N. E. Montaño, “Timing of planulation by pocilloporid corals in the northwestern Philippines," Marine Ecology Progress Series, vol. 370, pp. 111-119, 2008.

[24] S. Harii and H. Kayanne, "Larval dispersal, recruitment, and adult distribution of the brooding stony octocoral Heliopora coerulea on Ishigaki Island, southwest Japan," Coral Reefs, vol. 22, no. 2, pp. 188-196, 2003.

[25] I. Ne'eman, L. Fishelson, and Y. Kashman, "Sarcophine-a new toxin from the soft coral Sarcophyton glaucum (Alcyonaria)," Toxicon, vol. 12, no. 6, pp. 593-598, 1974.

[26] P. J. Mumby and R. S. Sterneck, "The resilience of coral reefs and its implications for reef management," in Coral Reefs: An
Ecosystem in Transition, Z. Dubinsky and N. Stambler, Eds., pp. 509-519, Springer, Amsterdam, The Netherlands, 2011.

[27] S. L. Romano, "Long-term effects of interspecific aggression on growth of the reef-building corals Cyphastrea ocellina (Dana) and Pocillopora damicomis (Linnaeus)," Journal of Experimental Marine Biology and Ecology, vol. 140, no. 1-2, pp. 135-146, 1990.

[28] P. J. Edmunds and R. Elahi, "The demographics of a 15year decline in cover of the Caribbean reef coral Montastraea annularis," Ecological Monographs, vol. 77, no. 1, pp. 3-18, 2007. 

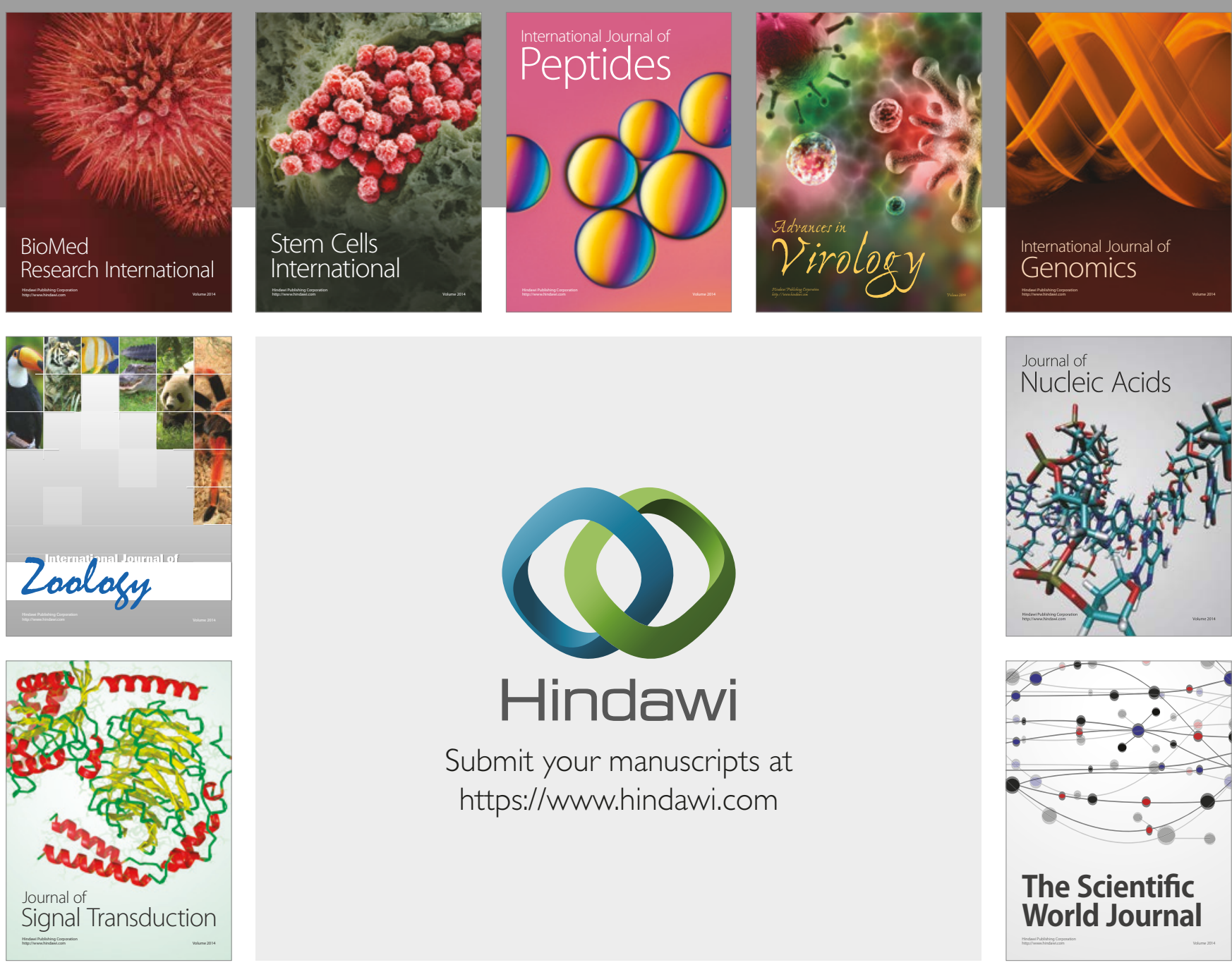

Submit your manuscripts at

https://www.hindawi.com
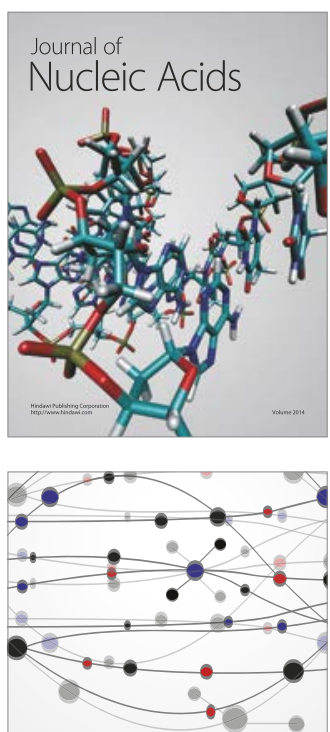

The Scientific World Journal

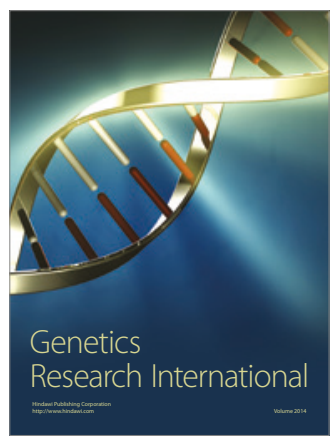

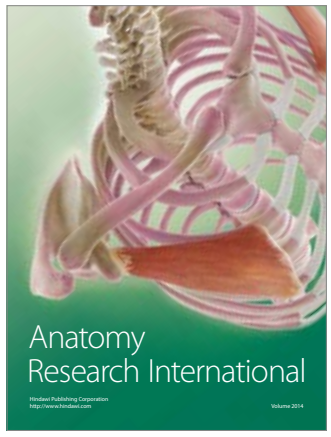

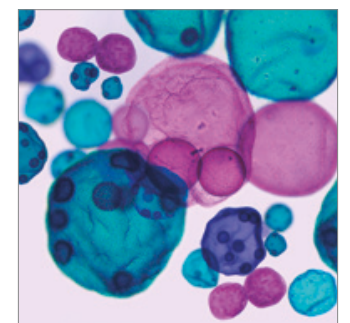

International Journal of Microbiology
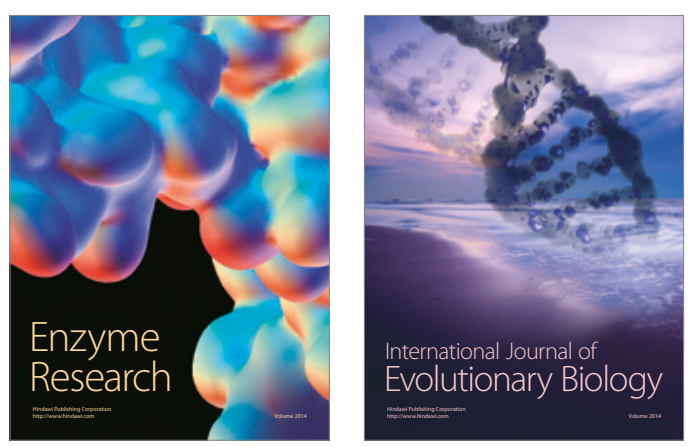
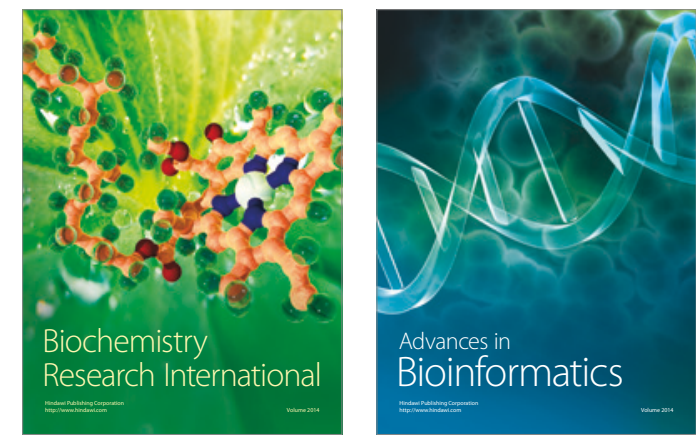

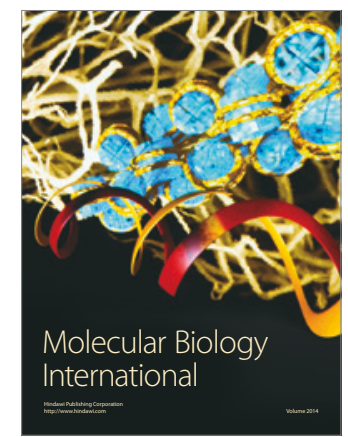

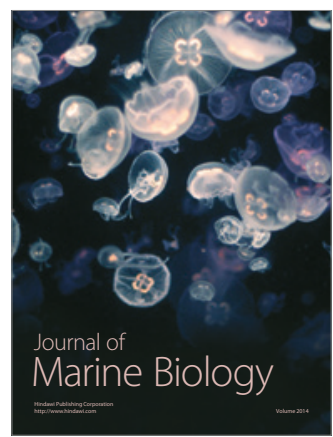

